\title{
ACIDEZ DEL SUELO PARA EL CULTIVO DE CAFÉ
}

Siavosh Sadeghian Khalajabadi *

Manejo de la acidez del suelo para optimizar la nutrición de su cafetal.

Una de las limitantes comunes para la producción de café en muchas regiones de Colombia es la acidez. Cuando las raíces del café se desarrollan en suelos ácidos su crecimiento es menor, son menos eficientes en la absorción de agua y nutrientes, y por lo tanto, las plantas son menos productivas.

La herramienta indispensable para el manejo de la acidez es el análisis de suelo, el cual ayuda a definir la dosis y la fuente de la enmienda (principalmente cales) para cada etapa del cultivo.

$\rightarrow$ La alternativa más efectiva para enfrentar este problema es el uso de cales, principalmente carbonatos de calcio y/o de magnesio.

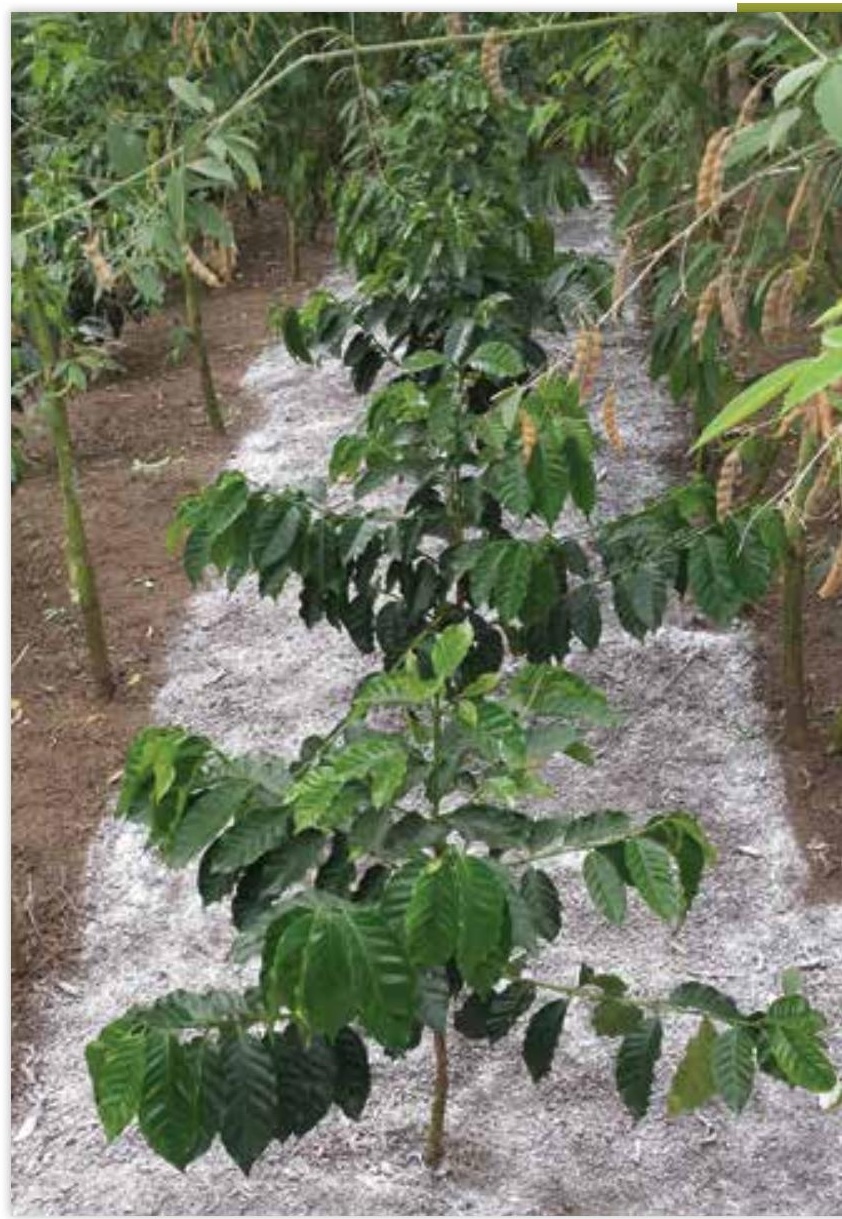

Sadeghian, S. (2021). Acidez del suelo para el cultivo de café. En Centro Nacional de Investigaciones de Café, Guía más agronomía, más productividad, más calidad (3a ed., pp. 95-99). Cenicafé. https://doi. org/10.38141/10791/0014_6 
- Como la cal no es soluble su efectividad está dada por la forma de su aplicación. Es mucho más eficaz si se incorpora al suelo, práctica que solo puede efectuarse al momento de la siembra, de lo contrario pueden ocasionarse daños a las raíces.

suelo ácido para café

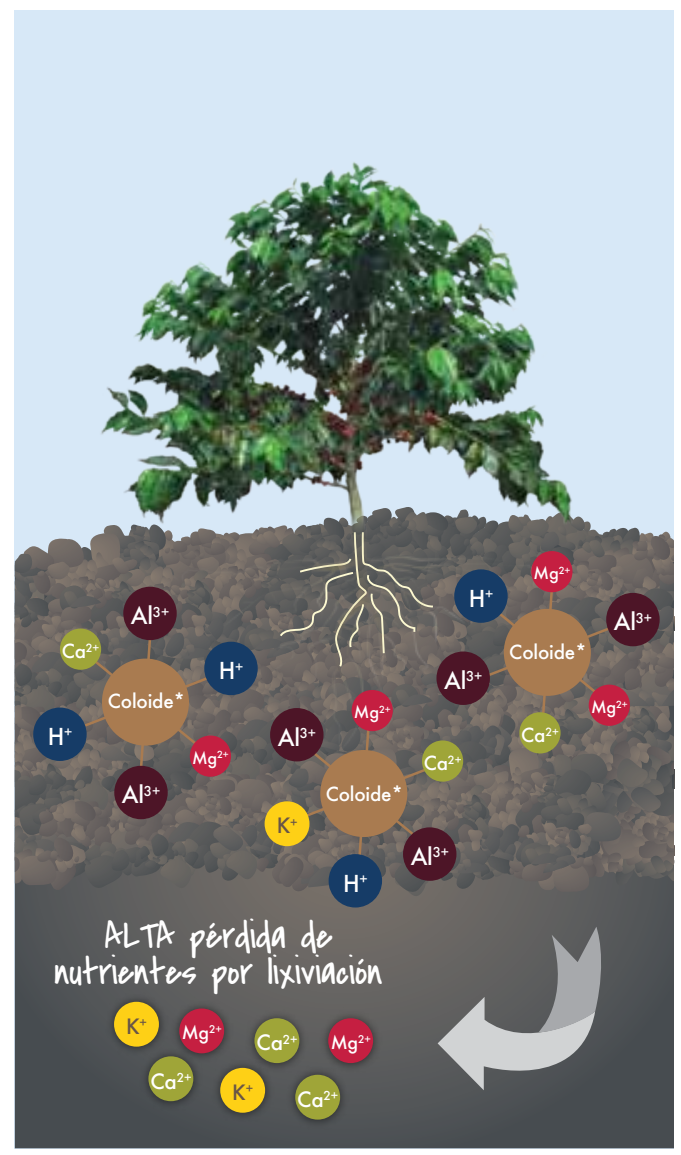

suelo con acidez adecuada para café

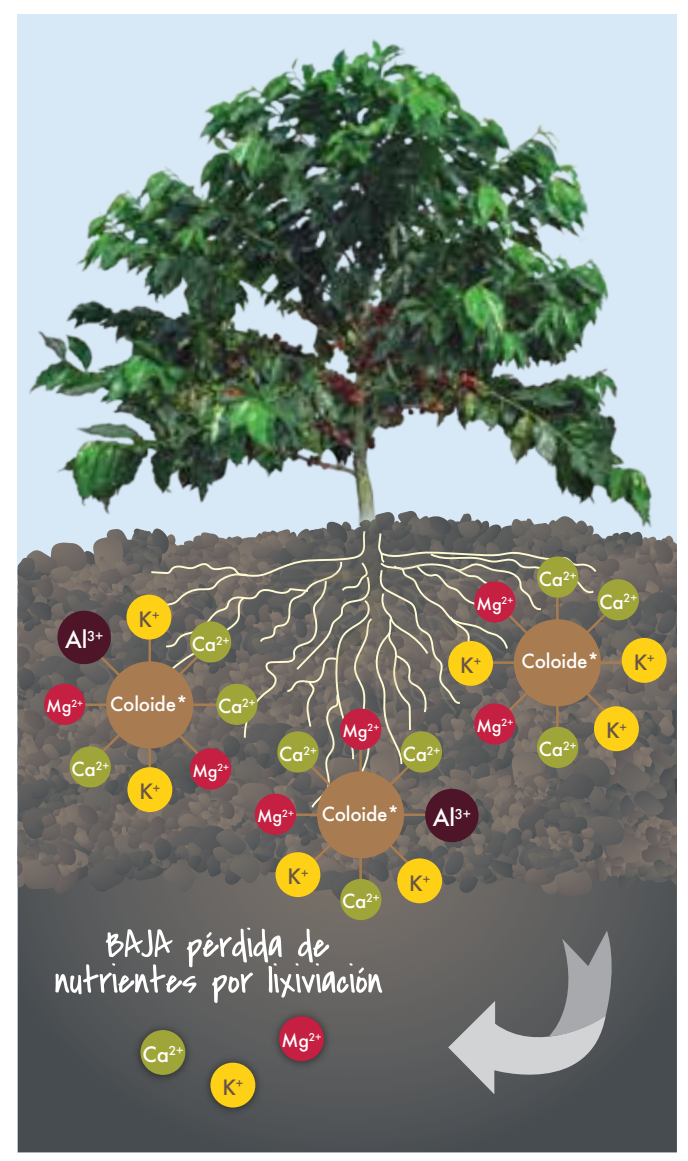

* Coloide órgano-mineral (arcilla y/o materia orgánica del suelo)

Menor capacidad de intercambio catiónico-CIC Menor disponibilidad de $\mathrm{Ca}^{2+} \mathrm{Mg}^{2+} \mathrm{K}^{+}$

Mayor toxicidad por $\mathbf{A}^{\mathbf{\beta}^{+}}$

Menor crecimiento radical

Mayores pérdidas por lixiviación
Mayor capacidad de intercambio catiónico-CIC Mayor disponibilidad de $\mathrm{Ca}^{2+} \mathrm{Mg}^{2+} \mathrm{K}^{+}$ Menor toxicidad por $\mathrm{A}^{\mathrm{l}+}$ Mayor crecimiento radical

Menores pérdidas por lixiviación

A ${ }^{3+}$ Aluminio 
$\rightarrow$ Cuando la cal no se mezcla de manera homogénea con el suelo antes de la siembra, se forman capas o costras de cal que no son efectivas. Esto también sucede al espolvorear el producto a las paredes del hoyo.

$\rightarrow$ El efecto de las aplicaciones superficiales se limita a los primeros 5 ó $10 \mathrm{~cm}$; sin embargo, se espera que las aplicaciones continuadas tengan efecto en mayores profundidades.

$\rightarrow$ Después de la siembra es necesario esparcir la cal de manera homogénea en la zona de raíces (el plato del árbol). Si el cultivo no ha alcanzado su máximo desarrollo, el área de aplicación debe ampliarse, teniendo en cuenta el crecimiento futuro.

$\rightarrow$ Es necesario retirar la mayor cantidad de hojarasca antes de encalar. El exceso de la hojarasca afecta la uniformidad de la aplicación de la cal.

- Cantidades de cal menores a las requeridas son menos efectivas $y$ el sobre-encalamiento afecta negativamente el crecimiento de las plantas, generando deficiencias de algunos elementos, principalmente de hierro, lo que se conoce como clorosis calcárea.

- Se sugiere llevar a cabo el encalamiento aproximadamente 2 meses antes o después de fertilizar sin fraccionar la dosis. Esta labor puede realizarse tanto en épocas de lluvia como secas.

En muchas regiones de Colombia la producción de café se afecta por la acidez del suelo. Tome las muestras de suelo para identificar y manejar los problemas de acidez. 


\section{Ta acidez del surlo}

\section{Manejo en la siembra del café}

\section{La acidez}

Es una condición del suelo

en la Que se presentan

valores bajos de $\mathrm{pH}$, toxicidad de aluminio $y$ bajos contenidos de calcio, magnesio y fósforo, afectando el crecimiento de las raices, la absorción de agua y nutrientes

Caficultor:

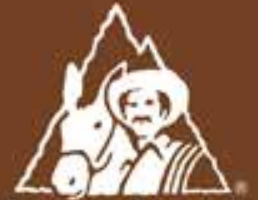

Pederacion Nacioaal de Cafeteros de Colombia

\section{¿Cómo manejarla?}

La acidez del suelo se corrige mediante la aplicación de enmiendas, principalmente cal agricola y cal dolomítica. Estos productos también suministran calcio y magnesio.

\section{¿Cuándo apliear enmiendas?}

El momento oportuno es en la siembra, cuando pueden mezclarse con el suelo del hoyo. Aunque la cal también puede aplicarse en los meses después de la siembra y de manera superficial en el plato del árbol, su efectividad es menor.

Realice el análisis de suelos para tomar decisiones acertadas para el encalado y asi corregir la acidez de suelos.

Consulte con su Extensionista 


\section{Fnmiendas para Eorregir la atiditz del suldo}
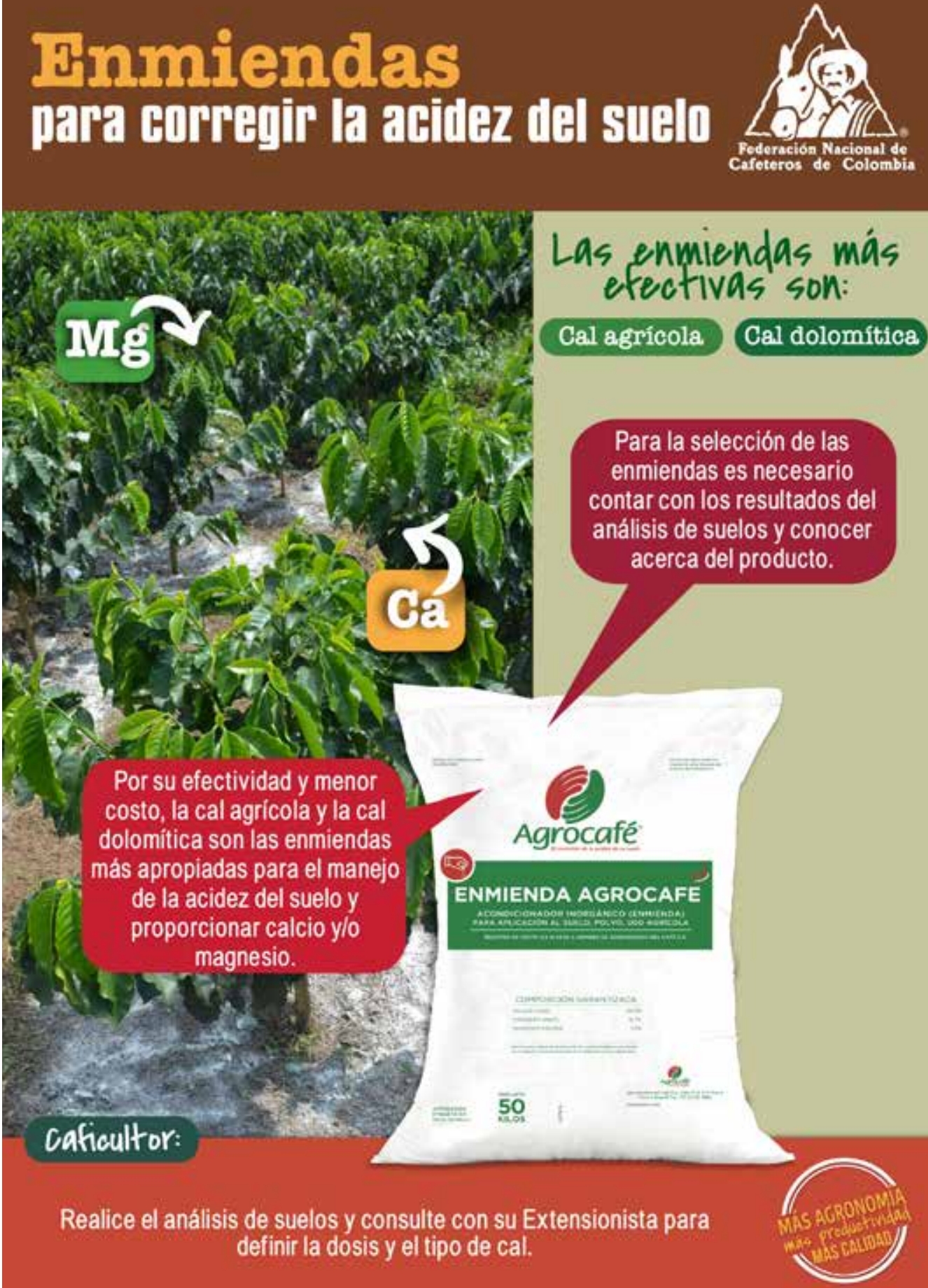